\title{
Biodegradation of $p$-chlorophenol by a microalgae consortium
}

\author{
Sofia A.C. Lima, M. Filomena J. Raposo, Paula M.L. Castro, Rui M. Morais*
}

Escola Superior de Biotecnologia, Universidade Católica Portuguesa, Rua Dr. António Bernardino de Almeida, Porto 4200-072, Portugal

Keywords: Adsorption; Biodegradation; p-chlorophenol; Microalgae; Zeolite

\begin{abstract}
An aquatic community was recovered from a waste discharge container fed with several aromatic pollutants. After 3 months of selective enrichment with $p$-chlorophenol and $p$-nitrophenol, two microalgae species, Chlorella vulgaris and Coenochloris pyrenoidosa, were recovered from the microbial consortium. As an axenic culture, this microalgae consortium was able to remove $p$-chlorophenol under different photo-regimes. Cultures grown under a $24 \mathrm{~h}$ light regime were capable of biodegrading $50 \mathrm{mg}^{-1}$ of $p$-chlorophenol within 5 days. Addition of zeolite, an adsorbing material, did not improve the $p$-chlorophenol removal. However, when $p$-chlorophenol at $150 \mathrm{mgl}^{-1}$ was fed to the culture supplemented with zeolite, the growth rate of the consortium improved, but the lag phase was longer (16 against 14 days in the absence of zeolite).
\end{abstract}

\section{Introduction}

Halogenated compounds represent one of the most predominant environmental pollutants, due to their widespread usage as biocides, fungicides, disinfectants, solvents and other industrial chemicals. Biodegradation of chlorinated phenols has been studied with pure and mixed bacterial cultures $[1,2]$. Only a few studies have shown that microalgae are able to biodegrade aromatic compounds [3]. Chlorella sp. was found to decolourise certain azo dyes and use them as carbon and nitrogen sources [4]. Semple and Cain [5] reported the degradation of phenol by Ochromonas danica. Luther [6] has reported that the alga Scenedesmus obliquus was able to utilise naphtalenesulphonic acids as a source of sulphur for their biomass, releasing the carbon ring into the medium. Three species of Chlorella were found to degrade pentachlorophenol [7], one of the species

\footnotetext{
Abbreviations: $p$-CP, p-chlorophenol; Chlorella vulgaris, Chl. vulgaris; Coenochloris pyrenoidosa, C. pyrenoidosa

*Corresponding author. Tel.: +351-225580001; fax: +351225090351.

E-mail address: rmorais@esb.ucp.pt (R.M. Morais).
}

mineralised up to $13.8 \%$ of $\left[\mathrm{UL}^{14} \mathrm{C}\right] \mathrm{PCP}$ to ${ }^{14} \mathrm{CO}_{2}$ within a 11-day incubation in a light-dark photo-regime. The biotransformation of 2,4,6-trinitrotoluene by an Anabaena sp. has been described [18]. The study of the role of microalgae in biodegradation systems is scarcely reported. A common approach used to treat organic compounds is a combination of biodegradation and adsorption processes. Adsorbing material, like zeolite or activated carbon, may be added to a biological process in order to improve the overall performance of the system and to increase the removal of the most recalcitrant organic material from wastewater $[8,9]$. Furthermore, zeolite has found particular significance in aquaculture, as it has a positive influence on the growth of the marine microalgae Nannochloropsis sp. $-75 \%$ higher cellular yields reported when cultivated in the presence of zeolite at $10 \mathrm{mg}^{-1}[10]$.

An axenic microalgae consortium was isolated from a waste discharge container fed with several aromatic pollutants. The capacity of the microalgae consortium to degrade and to grow on $p$-chlorophenol under different light regimes, was studied. Adsorption of $p$ chlorophenol onto zeolite is described and its effect on 
biodegradation rates by the microalgae consortium was evaluated.

\section{Materials and methods}

\section{Microbial community: growth conditions and degradative studies}

An aquatic microbial community was recovered directly from a waste discharge container fed with an undefined mixture of aromatic compounds, including nitrophenols, chlorophenols, and fluorobenzene, by adding a $50 \mathrm{ml}$ sample of the liquid waste to $50 \mathrm{ml}$ of minimal salts medium [2] in a $250 \mathrm{ml}$ Erlenmeyer. That container was kept near a window, without direct sunlight. Growth was promoted on a rotary shaker at $80 \pm 2 \mathrm{rpm}$ (Agitorb $300 \mathrm{~EB}, \mathrm{OMRON} \mathrm{H}^{\mathrm{E}} \mathrm{ER}$ ) within a controlled growth chamber at $25^{\circ} \mathrm{C}$ and $52.5 \mu \mathrm{mol}$ of photons $\mathrm{m}^{-2} \mathrm{~s}^{-1}$ (DataLogger LI-1000, LI-COR) photosynthetically active radiation (PAR) provided by cool white fluorescent lamps (L36 W/21 Hellweiss Luminux Coolwhite, Osram), set on a $24 \mathrm{~h}$-light photoregime. After 2 weeks of growth, the $100 \mathrm{ml}$ culture was transferred to a 11 -aerated flask and scaled-up to $800 \mathrm{ml}$ by successive additions of minimal salts medium. The degradative capacity of this microbial community was evaluated by adding different concentrations of $p$ chlorophenol ( $p$-CP), 25, 50 and $100 \mathrm{mgl}^{-1}$, to minimal salts medium, provided with an initial cell density of approximately $0.40-0.50 \mathrm{mg}^{-1}$ dry weight. Experiments were carried out with $100 \mathrm{ml}$ of culture in $250 \mathrm{ml}$ Erlenmeyers. Samples were taken every 2 days during a 15-day period. Inoculated medium free of $p-\mathrm{CP}$, and non-inoculated medium with the halo-aromatic compound, served as controls. Each biodegradation test was performed in triplicate.

\section{Isolation of the microalgae}

Two axenic morphologically different colonies, able to grow on plates containing $p$-CP, were isolated using the previously described methodology [11]. Each of the species was aseptically transferred in a laminar flow chamber (Bio48 FASTER, Italy) to liquid cultures. To further assess axenicity, a single cell was aseptically picked using a capillary pipette, with subsequent cultivation for the biodegradation studies. The isolated microalgae species were identified by morphological studies performed by the Department of Botany of the University of Coimbra.

\section{Degradation studies using the isolated microalgae}

All the following experiments were performed with the microalgae consortium resulting from the selective enrichment (composed of the two recovered species), which was supplied with $50 \mathrm{mgl}^{-1}$ of $p$-CP and incubated under different light photo-periods: $24 \mathrm{~h}$ light, $16 \mathrm{~h}$ light: $8 \mathrm{~h}$ dark, and $24 \mathrm{~h}$ dark, on a rotary shaker at $100 \pm 2 \mathrm{rpm}$. The experiments were carried out using $150 \mathrm{ml}$ of culture, in a $250 \mathrm{ml}$ round shaped flask. The inoculum added to the medium culture provided an initial cell density of ca. $1.8 \times 10^{6}$ cells $\mathrm{ml}^{-1}$. To follow $p$ $\mathrm{CP}$ removal, samples were taken every day during a 8 day period. A zeolitic product, used at $50 \mathrm{mgl}^{-1}$, was added to cultures supplemented with $p$-CP at 50, 100 or $150 \mathrm{mg} \mathrm{l}^{-1}$, using a $24 \mathrm{~h}$ light regime. All the experiments were carried out in triplicate. At $50 \mathrm{mgl}^{-1}$ of $p$-CP, the experiments were conducted during 5 days. Inoculated medium free of $p$-CP and free of zeolite served as controls. Cultures were incubated at $25^{\circ} \mathrm{C}$, under a $24 \mathrm{~h}$ light regime. Degradation studies of $p-\mathrm{CP}$ at 100 and $150 \mathrm{mgl}^{-1}$ were conducted in $150 \mathrm{ml}$ of medium provided with an initial cell density of $1.8-2.3 \times 10^{6}$ cells $\mathrm{ml}^{-1}$, and were followed during 31 days. Cultures were incubated at the above-mentioned conditions.

\section{Growth determinations}

Cell density (number of cells $\mathrm{ml}^{-1}$ ) was measured by microscopy, counting each culture twice in a Neubauer haemocytometer. Chlorophyll content was also determined. Prior to chlorophyll $a(\operatorname{chl} a)$ extraction (1:1) in $90 \%$ acetone (Merck) culture samples were centrifuged. Cellular disruption was promoted with glass beads followed by a $1 \mathrm{~min}$ period of vortexing (Heidolph REAX 2000), at room temperature in darkness. Cells were removed by centrifugation, and chl $a$ content was monitored by measuring the optical density of the supernatants at 664, 647 and $630 \mathrm{~nm}$ with a spectrophotometer (UV-Visible Spectrophotometer-Shimadzu, UV-1601). Using spectrophotometric equations [12], the chl $a$ content of the cultures was calculated as follows: [ $\mu \mathrm{g}$ of chl $a=11.85 *$ Abs664 -1.54*Abs647$0.08 \mathrm{Abs630]}$. At the beginning and at the end of the experiment biomass yields were also estimated by determining the dry weight $\left(\mathrm{mg} \mathrm{ml}^{-1}\right)$.

\section{Chlorophenol and ion chloride ions measurements}

The $p$-CP removal was detected by determining the residual $p$-CP by HPLC and by measuring the accumulation of chloride ion in the culture, as described previously [19]. Prior to HPLC analysis, the culture samples were centrifuged twice at $14000 \mathrm{rpm}$ for $5 \mathrm{~min}$.

\section{Adsorption of $\mathrm{p}$-chlorophenol to zeolite}

The adsorption of $p$-CP to zeolite was determined by incubating a series of $100 \mathrm{ml}$ Erlenmeyers containing $50 \mathrm{mgl}^{-1}$ of zeolite in $50 \mathrm{ml}$ of minimal salts medium 
supplemented with $p$-CP at $10-800 \mathrm{mg} 1^{-1}$. Cultures were incubated for $24 \mathrm{~h}$ light at $25^{\circ} \mathrm{C}$, on a rotary shaker. Samples were taken after $24 \mathrm{~h}$ and centrifuged at $14000 \mathrm{rpm}$ for $5 \mathrm{~min}$. The $p$-CP present in the supernatant was analysed by HPLC. The data were analysed using a Freundlich type isotherm: $[Q=k \mathrm{Cl} / n]$, where $Q$ represents the amount of $p$-CP adsorbed per mass of adsorbent $\left(\mathrm{mg} \mathrm{g}^{-1}\right)$, and $\mathrm{C}$ is the corresponding $p$-CP concentration in solution $\left(\mathrm{mgl}^{-1}\right)$. The Freundlich constants $k\left[\left(\mathrm{mg} \mathrm{g}^{-1}\right) /\left(\mathrm{mgl}^{-1}\right)^{1 / n}\right]$ and $1 / n$ (no dimensions) were obtained from a linear regression of the above equation. $k$ measures the adsorption capacity and the inverse of $1 / n$ measures for the adsorption intensity [20].

\section{Reagents}

All chemicals were of the highest purity grade available (Sigma Chemical Co., St. Louis, USA; Aldrich Chemical Co., Dorset, UK, Merck, Darmstadt, Germany, Romyl). Zeolite was obtained from FlukaBioChemika 96096 and it was sterilised by autoclaving prior to use.

\section{Statistical analysis}

Statistical analysis for the significant effect of zeolites and/or $p$-CP on the growth ratio was performed using Statistica (Anova/Manova) (StatSoft Inc., 1993). Significance between means was assessed by Tukey's Honest Significant Difference (HSD) test. Growth ratios were considered significantly different at $p<0.05$.

\section{Results and discussion}

\section{Degradation of $p$-chlorophenol by the microbial community}

Experiments carried out with the microbial community obtained directly from the waste discharge container resulted in the biodegradation of $p$-CP at 25, 50 and $100 \mathrm{mg}^{-1}$. Non-inoculated control cultures conducted throughout the experiments did not show any $p$-CP disappearance. Over a 15 day period of incubation, cultures supplied with the lower concentrations, 25 and $50 \mathrm{mg}^{-1}$, exhibited significant microalgae growth, while the cultures established at the highest concentration, $100 \mathrm{mg} \mathrm{l}^{-1}$, did not show microalgae growth. Growth of cultures with 25 and $50 \mathrm{mg} \mathrm{l}^{-1}$ of $p$-CP, measured as chl $a$ content, was, respectively, $35 \%$ and $81 \%$ higher, than growth obtained in a control non-supplemented culture. Biodegradation of $p-\mathrm{CP}$ by the microbial community was evident from the analysis of residual $p$-CP and chloride ion accumulation in the culture supernatant. Complete removal of $p$-CP from the cultures supplied with 25 and $50 \mathrm{mg}^{-1}$ of $p$-CP was observed after 9 days, whereas $100 \mathrm{mgl}^{-1}$ of $p$-CP were completely removed from the culture medium in 15 days. The stoichiometric amount of chloride ions released into the culture medium was concomitant with $p$-CP removal. It was not possible to infer from these experiments whether degradation was due to bacteria or microalgae, but the degradation potential of the microbial community was evident.

After an antibiotic treatment and a 3 months of selective enrichment with $p$-NP and $p$ - $\mathrm{CP}$, an axenic microalgae consortium was obtained. Using a cultivation dependent approach two microalgae species were recovered from the consortium and identified as Chlorella vulgaris (Chl. vulgaris) and Coenochloris pyrenoidosa (C. pyrenoidosa). Axenicity was assessed by microscopic observations, and bacterial growthbased tests, carried out by plating $100 \mu \mathrm{l}$ of culture samples onto NA, which further confirmed the axenic status of the cultures. Subsequently, all experiments were conducted using a microalgae consortium composed by the two recovered species as inoculum.

Inuence of light ont hep-chlorophenol degradation by the microalgae

Light is a very important parameter for microalgae growth. Three different photo-regimes, $24 \mathrm{~h}$ light, and $16 \mathrm{~h}$ light: $8 \mathrm{~h}$ dark and $24 \mathrm{~h}$ dark were studied with the microalgae consortium, supplied with $p$-CP at $50 \mathrm{mg}^{-1}$. In all photo-regimes, the non-inoculated medium containing $50 \mathrm{mg}^{-1}$ of $p-\mathrm{CP}$ remained unaltered during the time of the experiment. The first two photo-regimes led to cell growth and $p$-CP degradation, while the latter showed $p$-CP degradation while no growth was evident. No bacteria were recovered after plating samples taken during the experiment onto NA. Light microscopy analysis did not reveal the presence of microorganisms other than the inoculated microalgae. Figs. 1 and 2 show the growth patterns obtained with the microalgae cultures in a $24 \mathrm{~h}$ light and a $16 \mathrm{~h}$ light: $8 \mathrm{~h}$ dark, respectively. Cell density in the cultures supplied with $p$ $\mathrm{CP}$ increased only after degradation of the compound was accomplished (Fig. 1). The duration of the lag phase corresponded to the time needed for complete $p$-CP degradation to occur. During the initial 6 days of the experiment, chl $a$ content in the $24 \mathrm{~h}$ light and $16 \mathrm{~h}$ light: $8 \mathrm{~h}$ dark cultures containing $p$-CP was similar to that of non-supplemented controls. Then chl $a$ content increased significantly, 190 and $130 \%$ for $24 \mathrm{~h}$ light and $16 \mathrm{~h}$ light: $8 \mathrm{~h}$ dark cultures, respectively, in the cultures with $p$-CP. In $24 \mathrm{~h}$ dark cultures, chl $a$ content did not change during the 8 days of the experiment and no exponential phase was observed, not even after the complete disappearance of $p$-CP (data not shown). In all triplicates under the $24 \mathrm{~h}$ light regime, $p$-CP disappeared 
in 5 days (Fig. 1). The $16 \mathrm{~h}$ light: $8 \mathrm{~h}$ dark and $24 \mathrm{~h}$ dark presented different removal time periods within the triplicates: 3, 5, 7 (Fig. 2) and 4, 5, 7 days (results not shown), respectively. In all the cultures, $p$-CP was dechlorinated completely, as indicated by the stoichiometric accumulation of chloride in the medium and by determination of residual $p$-CP, however, this does not imply that the compound was fully mineralised. It is

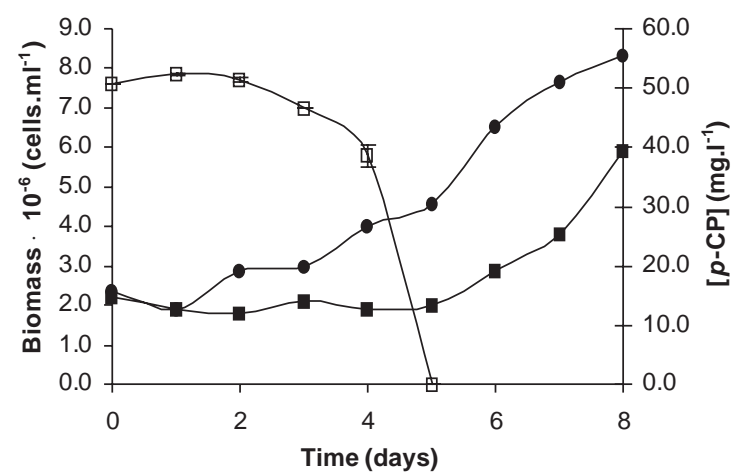

Fig. 1. Growth of axenic microalgae consortium in $24 \mathrm{~h}$ light at $25^{\circ} \mathrm{C}$ on $50 \mathrm{mg}^{-1} p$-CP $(\boldsymbol{\square})$ and without $p$ - $\mathrm{CP}(\bullet)$. The average of the disappearance of $p-\mathrm{CP}$ in all the triplicates was represented $(\square)$.

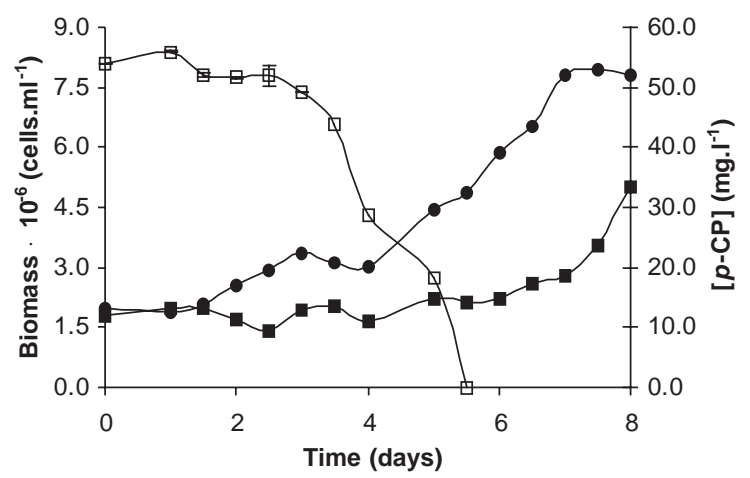

Fig. 2. Growth of axenic microalgae consortium in $16 \mathrm{~h}$ light: $8 \mathrm{~h}$ dark at $25^{\circ} \mathrm{C}$ on $50 \mathrm{mg}^{-1} p$-CP $(\boldsymbol{\square})$ and without $p$-CP $(\bullet)$. The disappearance of $p-\mathrm{CP}$, in one of the triplicates, was represented $(\square)$. possible that biotransformation products were accumulated in the medium; the fact that the cultures grown in the dark were not able to grow while $p$-CP was degraded may indicate that under those conditions biotransformation products were not incorporated into biomass. Triplicates from each experimental culture had the same inoculum source, but the relative amount of each species in the consortium may differ, which may explain the variations for the biodegradation rates observed within the triplicates. In previous studies we have seen that the ratio between different microalgae species can be determinant in the degradation process [11].

\section{Inuence of zeolite in the microalgae consortium growth and $\mathrm{p}$-chlorophenol biodegradation}

Adsorption studies made with zeolite and 4-CP demonstrated the high adsorptive capacity of the material. Freundlich constants $k$ and $1 / n$ obtained were $15.628\left[\left(\mathrm{mg} \mathrm{g}^{-1}\right) /\left(\mathrm{mg} \mathrm{l}^{-1}\right)^{1 / n}\right]$ and 0.77 , respectively. $k$ represents the adsorption capacity and $n$ (in this case 1.30) the system suitability, for which values higher than 1 represent favourable adsorption conditions [13].

Under a light photo-regime, the growth of the microalgae consortium cultivated in the presence of zeolite, and supplemented with 100 and $150 \mathrm{mg}^{-1}$ of $p$ $\mathrm{CP}$, was evaluated. Regardless of the zeolite addition, the presence of $p$-CP led to an increase in the cell growth rate, although cultures with 100 and $150 \mathrm{mgl}^{-1}$ of $p$-CP presented a much longer lag phase than the ones without $p$-CP (Table 1), which is consistent with what was observed in previous experiments (Fig. 1). After 16 days, a statistically significant higher increase in biomass was observed in cultures supplemented with $100 \mathrm{mg}^{-1} p$-CP; however, by that time, the culture supplemented with $150 \mathrm{mg}^{-1} p$-CP was still in the lag phase. Within 30 days, all the $p$-CP supplemented cultures exhibited statistically significant higher biomass levels than the control cultures. This may indicate that intermediates of degradation of $p$-CP were incorporated into biomass. Moreover, the fact that exponential growth phase only started after complete degradation of $p$-CP may indicate that detoxification of $p$-CP by the axenic microalgae culture leads to an increase on the biomass. Other studies have shown that Thalassiosira sp. was also

Table 1

Comparison of growth rates and lag phase duration determined for consortium cultures in the presence of zeolite at $50 \mathrm{mg}^{-1}$

\begin{tabular}{lllllr}
\hline & \multicolumn{2}{l}{ With zeolite } & & \multicolumn{2}{l}{ Without zeolite } \\
\cline { 2 - 3 } \cline { 5 - 6 } & Growth rate & Lag phase (days) & & Growth rate & Lag phase (days) \\
\hline Control & $0.063 \pm 0.006$ & $2.0 \pm 0.0$ & & $0.071 \pm 0.003$ & $2.0 \pm 0.0$ \\
$100 \mathrm{mg} \mathrm{l}^{-1} p$-CP & $0.083 \pm 0.014$ & $13.0 \pm 0.0$ & & $0.102 \pm 0.005$ & $12.0 \pm 1.8$ \\
$150 \mathrm{mgl}^{-1} p$-CP & $0.114 \pm 0.007$ & $16.0 \pm 0.0$ & & $0.104 \pm 0.011$ & $14.7 \pm 1.2$ \\
\hline
\end{tabular}


capable of dechlorinating monochlorophenols, 3,5dichlorophenol, and 2,4,6-thichlorophenol [14]. Semple and Cain [5] observed that Ochromonas danica grew heterotrophically on phenol or $p$-cresol as the sole carbon source. Phenol was never detected in our cultures. Within 5 days, the consortium was able to accomplish complete removal of 50 and $100 \mathrm{mgl}^{-1}$ of $p$ $\mathrm{CP}$, either with or without zeolite supplementation (data not shown). When the $p$-CP concentration was increased to $150 \mathrm{mg}^{-1}$, biodegradation of the halogenated compound occurred within ca. 9 days in the absence of zeolite (Fig. 3). In the presence of zeolite, within 9 days, biodegradation of ca. $80 \%$ of the initial $150 \mathrm{mg} \mathrm{l}^{-1}$ of $p$ chlorophenol was observed, although no $p$-CP was detected in the medium from day 7 , when chloride release only accounted for ca. 50\% biodegradation of the compound. The zeolite adsorbed temporarily the $p$ $\mathrm{CP}$ leaving it available for subsequent biological degradation. A residual amount of the compound remained adsorbed to zeolite $(40 \mathrm{mg} p$-CP per gram of zeolite for $2000 \mathrm{mg} \mathrm{g}^{-1}$ supplied, and $560 \mathrm{mgg}^{-1}$ for $2947 \mathrm{mg} \mathrm{g}^{-1}$ of $p$-CP supplied, after 6 and 9 days, respectively), which was not available for biological degradation within the time of the experiment, 31 days (Table 2). This phenomenon is more evident at the highest amount of $p$-CP supplied $150 \mathrm{mg}^{-1}$ (22.1 mg of

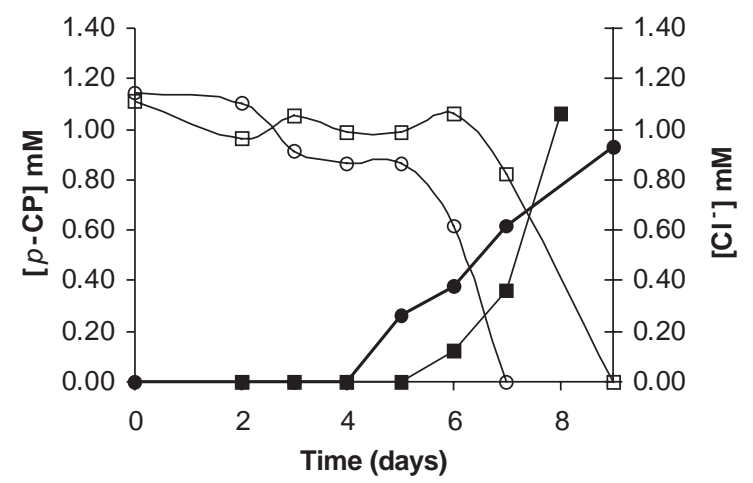

Fig. 3. Degradation of $1.17 \mathrm{mM}$ (or $150 \mathrm{mgl}^{-1}$ ) of $p$-chlorophenol as indicated by $\left[\mathrm{Cl}^{-}\right](\mathrm{mM})$ released in the presence $(\bullet)$ and absence $(\mathbf{\square})$ of zeolite and disappearance of compound supplied $[p-\mathrm{CP}](\mathrm{mM})$ in cultures with $(\mathrm{O})$ and without zeolite ( $\square)$ throughout time.
$p$-CP loaded resulting in $17.9 \mathrm{mg}$ of $p$-CP biodegraded). The high adsorption capacity of zeolite serves to damp high loads of the compound. In this type of system the biomass is active even at very low concentrations of target organic chemicals. This makes it less sensitive to the presence of toxic and inhibitory materials, and more resistant to shock loading of toxics than dispersed growth systems $[9,15]$. Phenol and chlorinated phenols are more effectively biodegraded by immobilised rather than suspended bacteria [16] and chlorophenol degradation by matrix-bond fungi has also been described [17]. In our study, microalgae consortium associated with zeolite could degrade $p-\mathrm{CP}$ present in the culture medium and $p$-CP adsorbed onto the zeolite matrix, which remained bioavailable.

\section{Conclusion}

After three months of selective enrichment, an axenic culture of two microalgae species, Chl. vulgaris and $C$. pyrenoidosa, was obtained from a waste discharge container fed with several aromatic pollutants. This consortium was used to study the $p$-chlorophenol biodegradation capacity of the microalgae. The microalgae consortium was able to remove $p$-chlorophenol under different photo-regimes. However, exponential growth did not occur under the $24 \mathrm{~h}$ dark condition, and under light conditions ( $24 \mathrm{~h}$ and $16: 8 \mathrm{~h}$ ) it only occurred after biodegradation of the $p$-chlorophenol. Cultures grown under a $24 \mathrm{~h}$ light regime were capable of biodegrading $50 \mathrm{mg} \mathrm{l}^{-1}$ of $p$-chlorophenol within 5 days. Addition of zeolite, an adsorbing material, did not improve the $p$-chlorophenol removal. However, when $p$ chlorophenol at $150 \mathrm{mgl}^{-1}$ was fed to the culture supplemented with zeolite, the growth rate of the consortium improved, but the lag phase was longer (16 against 14 days in the absence of zeolite). Within 9 days, complete biodegradation of $p$-chlorophenol was observed for cultures non-supplemented with zeolite, while biodegradation of ca. $80 \%$ was detected after the same period of time for supplemented cultures, as indicated by the release of chloride. An adsorption effect was visible at this concentration, contributing to the slower rate of biodegradation; after 7 days the $p$-chlorophenol was

Table 2

Amount of $p$-CP available after adsorption to zeolite. Table shows $p$-CP supplied, the amount of $p$-CP per $\mathrm{g}$ zeolite, $p$-CP remaining adsorbed after 6 and 9 days for 100 and $147 \mathrm{mgl}^{-1}$ of $p$-CP, respectively, and $p$-CP biodegraded

\begin{tabular}{lllll}
\hline $\begin{array}{l}\text { Initial }[p \text {-CP }] \text { in the } \\
\text { culture }\left(\mathrm{mg}^{-1}\right)\end{array}$ & $\begin{array}{l}p \text {-CP loaded } \\
(\mathrm{mg})\end{array}$ & $\begin{array}{l}\text { mg } p \text {-CP loaded } \\
\text { per g zeolite }\end{array}$ & $\begin{array}{l}p \text {-CP remaining } \\
\text { adsorbed }(\mathrm{mg} / \mathrm{g})\end{array}$ & $\begin{array}{l}p \text {-CP biodegraded } \\
(\mathrm{mg})\end{array}$ \\
\hline 100 & 15.0 & 2000 & 40 & $14.7(98)^{\mathrm{a}}$ \\
147 & 22.1 & 2947 & 560 & $17.9(81)^{\mathrm{a}}$ \\
\hline
\end{tabular}

\footnotetext{
${ }^{\mathrm{a}}$ The values in parenthesis indicate percentage of $p$-CP biodegraded.
} 
removed from the cultures supernatant. $p$-chlorophenol adsorbed by the zeolite was subsequently bioavailable for biodegradation.

\section{Acknowledgements}

The authors would like to thank the financial support of Ministério da Defesa Nacional, Programa Ambiente e Defesa through the project Mare Nostrum.

\section{References}

[1] Hardman DJ. Biotransformation of halogenated compounds. Criti Rev Biotechnol 1991;11:1-40.

[2] Carvalho MF, Vasconcelos I, Bull AT, Castro PML. A GAC biofilm reactor for the continuous degradation of 4-chlorophenol: treatment efficiency and microbial analysis. Appl Microbiol Biotechnol 2001;57:419-26.

[3] Semple KT, Cain RB, Schmidt S. Biodegradation of aromatic compounds by microalgae. FEMS Microbiol Lett 1999;170:291-300.

[4] Jinqi I, Houtian O. Degradation of azo dyes by algae. Environ Pollut 1992;75:273-8.

[5] Semple KT, Cain RB. Biodegradation of phenols by the alga Ochromonas danica. Appl Environ Microbiol 1996;62(4):1265-73.

[6] Luther M. Degradation of different substituted aromatic compounds as nutrient sources by the green alga Scenedesmus obliquus. Dechema Biotechnol Conf 1990;4: 613-5.

[7] Tikoo V, Scragg AH, Shales SW. Degradation of pentachlorophenol by microalgae. J Chem Technol Biotechnol 1997;68:425-31.

[8] Armenante PM, Colella LS, Kafkewitz D, Larkin MJ. Effect of a biofilm on the adsorption of 4-chlorophenol on activated carbon. Appl Microbiol Biotechnol 1996;46: $667-72$.
[9] Shi J, Zhao XD, Hickley RF, Voice TC. Role of adsorption in granular activated carbon-fluidised bed reactors. Water Environ Res 1995;67:302-9.

[10] Ruiz JL, Lopez-Alcata JM. Zeolitc nature products: culture of marine microalgae. J. Shellfish Res 1988;17(1):338.

[11] Lima, SAC, Castro, PML, Morais, R. M. Biodegradation of p-nitrophenol by microalgae. J Appl. Phycol 2003; 15:137-142.

[12] Jeffrey SW, Humphrey GF. New spectrophotometric equations for determining chlorophylls $\mathrm{a}, \mathrm{b}, \mathrm{c}_{1}$ and $\mathrm{c}_{2}$ in higher plants, algae and natural phytoplankton. Biochem Physiol Pflanzen 1975;164:191-4.

[13] Treybal RE. Mass transfer operations, 3rd ed. New York: McGraw-Hill; 1980

[14] Lovell CR, Ericksen NT, Lewitus AJ, Chen YP. Resistance of the marine diatom Thalassiosira sp. to toxicity of phenolic compounds. Mar Ecol Prog Ser 2002;229:11-8.

[15] Fauzi AM. Process development for biotreatment of very low concentrations of halo-organic chemicals. Ph.D. Thesis, University of Kent, Canterbury, 1995.

[16] Lee CM, Lu CJ, Chuang MS. Effects of immobilised cells on the biodegradation of chlorinated phenols. Water Sci Technol 1994;30:87-90.

[17] Ullah MA, Kadhim H, Rastall RA, Evans CS. Evaluation of solid substrates for enzyme production by Coriolus versicolor, for use in bioremediation of chlorophenols in aqueous effluents. Appl Microbiol Biotechnol 2000;54:832-7.

[18] Pavlostathis SG, Jackson GH. Biotransformation of 2,4,6trinitrotoluene in a continuous-flow Anabaena sp system. Water Res 2002;36(7):1699-706.

[19] Caldeira M, Heald SC, Carvalho MF, Vasconcelos I, Bull AT, Castro PML. 4-Chlorophenol degradation by a bacterial consortium: development of a granular activated carbon biofilm reactor. Appl Microbiol Biotechnol 1999;52:722-9.

[20] Jonge RJ, Breure AM, van Andel JG. Reversibility of adsorption of aromatic compounds onto powdered activated carbon (PAC). Water Res 1996;30(4):883-92. 